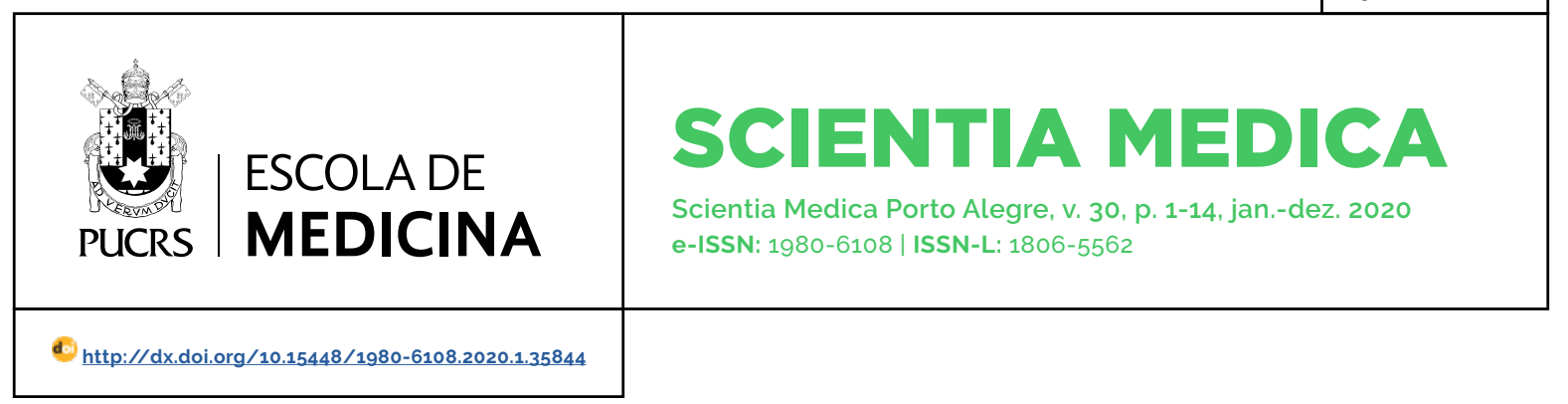

ORIGINAL ARTICLE

\title{
Plasma antioxidant substances apparently do not influence the radiodermatitis occurrence
}

\author{
Substâncias antioxidantes do plasma aparentemente não influenciam a ocorrência de \\ radiodermatite
}

\section{Guilherme Costa Munhoz ${ }^{1}$}

orcid.org/0000-0003-3896-9370

munhozgc@gmail.com

\section{Gustavo Viani Arruda orcid.org/0000-0002-4337-7575 gusviani@gmail.com}

\section{Marcela Maris Madeira Lana Soares ${ }^{1}$}

orcid.org/0000-0003-3920-2403 marcelammadeira@hotmail.com

\section{Dayanne Guttmann Batista $^{1}$}

orcid.org/0000-0003-0522-1833

dayanneguttmann@gmail.com

\section{Agnaldo Bruno Chies} orcid.org/0000-0001-9263-2475 agnaldochies@hotmail.com

Received on: Sep.30th 2019. Approved on: May. 16 $6^{\text {th }}, 2020$. Published on: Sep. $17^{\text {th }}, 2020$

\section{(c) (1)}

Artigo está licenciado sob forma de uma licença Creative Commons Atribuição 4.0 Internacional.

\section{ABSTRACT}

AIMS: Radiation affects not only tumors but also healthy tissues through the increment of oxidative stress. Thus, this study aimed to evaluate the oxidative stress degree as well as non-enzymatic antioxidant defenses in the plasma of patients submitted to radiotherapy and to verify if these parameters are modified in those patients who develop radiodermatitis.

METHODS: Forty-one patients submitted to radiotherapy for treatment of breast cancer were followed. From these patients, plasma samples were obtained at the beginning, in the middle and at the end of the treatment, for analysis of thiobarbituric acid reactive substances (TBARS) and ferric reducing ability of plasma (FRAP).

RESULTS: No significant differences were observed in terms of TBARS and FRAP in plasma harvested from these patients at the beginning and at the middle of the treatment. There was lower incidence of grade two radiodermatitis among patients undergoing radiotherapy with hypofractionated doses. There were no differences in FRAP or TBARS among patients who developed radiodermatitis of any degree in relation to those who did not develop this side effect. No differences of FRAP or TBARS were observed between patients that presented grade two radiodermatitis regarding to the others studied.

CONCLUSION: There was no clear relationship between changes in TBARS or FRAP with the occurrence or severity of radiodermatitis.

KEY WORDS: Breast cancer. Oxidative stress. Radiotherapy. Thiobarbituric acid reactive substances. Radiodermatitis.

ABBREVIATIONS: 3D, three-dimensional; BHT, butyl toluene; $\mathrm{CT}$, Computed tomography;

CTC, common terminology of adverse event criteria; DNA, deoxyribonucleic acid; EBCTCG, Early Breast Cancer Trialist's Collaborative Group; FAMEMA, Faculdade de Medicina de Marilia; FRAP, Ferric Reducing Ability of Plasma; $\mathrm{Hb}$, hemoglobin; INCA, Instituto Nacional de Câncer; MDA, malondialdehyde; RT, radiotherapy; RTOG, Radiation Therapy Oncology Group; SDS, sodium dodecyl sulfate; TBA, thiobarbituric acid; TBARS, Thiobarbituric Acid Reactive Substances: TCA, trichloroacetic acid.

\section{Introduction}

The cancer's world prevalence has increased in recent years, largely because of aging and the population growth, associated mainly with a lifestyle influenced by some already known carcinogenic factors such as smoking and sedentarism [1]. Worldwide, breast cancer is the most 
prevalent $(24.2 \%)$ and the first leading cause of death among women, being the second leading cause of cancer death in both genders in Brazil. Moreover, it is estimated that in 2020 will be 66280 new cases of breast cancer in Brazil [2,3].

Radiotherapy (RT) has a pivotal role in the treatment of breast cancers. In the meta-analysis named EBCTCG (Early Breast Cancer Trialist's Collaborative Group), women underwent mastectomy and axillary emptying (with one to three affected lymph nodes) that were treated with RT after surgery showed a drastic reduction in locoregional recurrence rates and survival, either associated with chemotherapeutic treatment or not. According to this meta-analysis, RT is a fundamental part of the treatment to guarantee good results [4,5].

In our Department, the radiotherapy treatment is all guided by computed tomography (CT) images. After the delimitation of both the tumor and the normal structures around it, the doses are planned through calculus software. However, even with this technical planning, RT's side effects cannot be discarded. Side effects produced by radiation are classified in acute and chronic. Acute side effects are those that occur during treatment or up to 90 days after initiating it. One of the main acute side effects of breast cancer is radiodermatitis. This effect is triggered by ionizing radiation-induced intracellular alteration. These radiation-induced intracellular alterations are either direct or indirect, upon molecules of deoxyribonucleic acid (DNA) [6]. Actually, tissues have different levels of radiosensitivity [7].

Radiation-induced direct effects, which correspond to a quarter of the damage produced in cell macromolecules, occur through collision of the photon with the DNA molecule, what breaks its double-strand. Radiation-induced indirect effects, responsible for most of the cellular damage, involves free radicals produced by the breakdown of hydrogen bonds of water molecule. Since water represents about $80 \%$ of the intracellular environment, the huge amount of free radicals that are produced in consequence of radiation causes a redox imbalance in the cell. As a consequence of this imbalance, it occurs cellular damage not only in the tumor but also in healthy tissues, thereby leading the side effects of the treatment. One of the most lethal radiation-induced modifications to the cells occurs in consequence of the reaction of free radicals with DNA that leads breakdown of its double-strand [6, 8-13].

On the other hand, free radicals are also products of the metabolism and have physiological functions such as phagocytosis, blood pressure control, cell signaling and apoptosis. However, in excess, they may cause cell damage by binding to constituent macromolecules such as carbohydrates, DNA, proteins and lipids. To keep under control the free radicals levels, there are antioxidant mechanisms in the body. Nevertheless, when the production of free radicals exceeds the capacity of the antioxidant defenses, it is established a pathophysiological condition called oxidative stress that leads to cellular damage [14].

The body's antioxidant defenses can be divided into enzymatic and non-enzymatic. The non-enzymatic defenses are due the presence of substances such as uric acid, vitamin $\mathrm{C}$ and albumin, that confer antioxidant properties to the body's fluids [15]. There are methods to evaluate the "antioxidant potency" of these non-enzymatic defenses present in biological fluids. One of these methods, FRAP (ferric reducing ability of plasma), is the determination of the plasma's ability to reduce the ferric ion (Felll) to ferrous ion (Fell). Uric acid and vitamin C exert respectively $60 \%$ and $20 \%$ of the antioxidant capacity evaluated by this method [14-16]. The FRAP provides more biologically relevant information than the isolated dosing of the substances that make it up. This method is considered inexpensive, the reagents are simple to prepare, the results are highly reproducible and the procedure is simple and fast. For these reasons the FRAP has been increasingly used in research of oxidative stress and its effects [14]. However, this method has some limitations because not every antioxidant can reduce the ferric ion and not every substance present in the plasma, capable of reducing the ferric ion, is an antioxidant. In addition, FRAP measures only non-enzymatic antioxidant defenses [14, 16]. In parallel, there are also techniques for 
the quantification of oxidative stress. The body undergoes oxidative stress generates high levels of lipid peroxidation products, such as lipid hydroperoxide, malondialdehyde (MDA) and nitric oxide metabolites. One of the most used technic of quantification of oxidative stress is the TBARS (thiobarbituric acid reactive substances) [17, 18]. This method quantifies the concentration of MDA in the medium by spectrophotometry $[14,16]$.

Finally, considering the presented arguments, RT induces both therapeutic and side effects through the increment of intracellular free radicals. Moreover, there are antioxidant defenses in order to keep under control the free radicals concentration in the body. Thus, the present study questions whether non-enzymatic antioxidant defenses present in the body can influence the adverse effects of RT. The answer to this questioning may be clinically useful because the ability to predict some possible predisposition to RT-induced side effects could guide the medical decisions.

\section{Methods}

\section{Study type}

Prospective cohort study, conducted at the Department of Radiotherapy and Oncology, in Faculdade de Medicina de Marilia (FAMEMA). The correlated variables were the antioxidant defenses of the organism and the oxidative stress generated in the radiotherapy treatment with the presence or not of radiodermatitis. The period of follow-up of the patients was from the beginning of the radiotherapy treatment until the end.

\section{Inclusion criteria}

Patients with a diagnosis of breast cancer, without previous RT treatment, including those underwent adjuvant RT, with or without partial or radical mastectomy. The study had no restrictions of age, gender or ethnicity.

\section{Exclusion criteria}

Patients with a history of previous treatment for any other neoplasia, renal failure, liver dysfunction and/or heart failure, as well as those with metastatic disease.

\section{Radiotherapy procedure}

RT was performed using the three-dimensional (3D) technique, with a $6 \mathrm{mV}$ photons beam. All cases were submitted in the CT simulation, with initial tumor volume evaluation. CT was acquired with $3 \mathrm{~mm}$ cuts, from the cricoid cartilage up to the $L 3$ vertebra. In planning the breast was circumvented, as well as the lymphatic drainage and organ at risk such as heart, lungs, esophagus and thyroid. In cases of mastectomy, the delimitation of the volume of treatment was the plastron, according to the guideline of the RTOG (Radiation Therapy Oncology Group). In order to facilitate the analysis of the adverse effects, the doses of RT were stratified in: hypofractionated dose, which corresponded to 42.5 Gy administered over 16 sessions, and conventional dose, having a maximum of 55 Gy administered over 30 sessions. Treatment verifications were performed through a digital film portal once a week.

\section{FRAP}

For the determination of the antioxidant capacity by FRAP, blood samples were harvested from each patient at the beginning ( $\mathrm{T}_{1}$ ), the middle ( $\left.\mathrm{T}_{2}\right)$ and the last day of treatment (T3), in heparinized tubes. Later, these blood samples were centrifuged at 3000 rpm for 10 minutes at a controlled temperature at $4^{\circ} \mathrm{C}$. The plasma samples were then harvested and stored at $-80^{\circ} \mathrm{C}$ until the day of the FRAP assay.

The FRAP assay was performed through three solutions: A (Acetate buffer: $300 \mathrm{mM}, \mathrm{pH} 3.6$ and $40 \mathrm{mM} \mathrm{HCl}$ ), B (TPTZ-2,4,6-tri [2-pyridyl]-s-triazine-10 $\mathrm{mM}$ ) and $\mathrm{C}$ (ferric chloride hexahydrate - FeCl $3.6 \mathrm{H} 2 \mathrm{O}-20 \mathrm{mM}$ ), forming the working reagent $A+B+C$ in the ratio 10: 1: $1(V / V)$. Samples were added to the working reagent and read in a spectrophotometer microplate reader at 593nm.

The FRAP concentrations were estimated by interpolating the determined absorbances in the samples with those determined in a standard curve, that was prepared through the dilution of ferrous sulfate (FeSO4) in distilled water, thereby obtaining final concentrations $0,31.25,62.5,125$. 250, 500, 1000 mol/L. 


\section{Plasma constituents that determine FRAP}

In the present study, it was also necessary to know the plasma concentrations of uric acid, vitamin C, albumin and hemoglobin, since these constituents that determine the FRAP values. Plasma levels of uric acid, albumin and hemoglobin were obtained from the routine hospital service.

Plasma concentrations of vitamin $C$ were determined in samples from these patients, in parallel to FRAP. For this analysis, $200 \mu$ lof plasma were placed in tubes containing $800 \mu \mathrm{l}$ of $5 \%$ trichloroacetic acid (TCA) and allowed to stand in an ice bath for five minutes. This acidified plasma was then centrifuged for 10 minutes at $2500 \mathrm{rpm}$. In the sequence, $300 \mu \mathrm{l}$ of the collected supernatant were added to $100 \mu \mathrm{l}$ of color reagent Idinitrophenylhydrazine-DNPH 2\%, thiourea $5 \%$ and copper sulfate pentahydrate $(0.78$ $\mathrm{g}$ dissolved in $40 \mathrm{ml}$ of $25 \% \mathrm{H}_{2} \mathrm{SO}_{4}$ ) in the ratio of 20:1:1. In parallel, a tube containing $300 \mu \mathrm{l}$ of distilled water and $100 \mu \mathrm{l}$ of $65 \%$ sulfuric acid $\left(\mathrm{H}_{2} \mathrm{SO}_{4}\right)$ was prepared (white tube). The reaction was incubated at $37^{\circ} \mathrm{C}$ for four hours sheltered from light, followed by a 15 minute ice bath. At the end of the ice bath, 485 ul of $65 \% \mathrm{H}_{2} \mathrm{SO}_{4}$ was added. After 20 minutes at room temperature and sheltered from light, the spectrophotometric reading was carried out at 520 $\mathrm{nm}$. The vitamin C concentrations were estimated by interpolating the determined absorbances in the samples with those determined in a standard curve obtained with ascorbic acid diluted in 5\% metaphosphoric acid at concentrations $0,0.25,0.5$. 1.0, $2.0,3.0$ and $4.0 \mathrm{mg} / \mathrm{dl}$.

\section{TBARS}

The oxidative stress was measured in the plasma samples by the quantification of the end products of lipid peroxidation through the TBARS technique [19]. For this analysis, $100 \mu \mathrm{L}$ of plasma sample was added to $10 \mu \mathrm{L}$ of butyl toluene (BHT) and then to a solution containing $100 \mu \mathrm{l}$ of $10 \%$ sodium dodecyl sulfate (SDS), $300 \mu$ of distilled water, $750 \mu \mathrm{l}$ of $20 \%$ acetic acid and $750 \mu \mathrm{l}$ of thiobarbituric acid (TBA). This solution was incubated in a water bath at $90-100^{\circ} \mathrm{C}$ for 60 minutes and then placed in an ice bath for 15 minutes to terminate the reaction. Finally, this solution was centrifuged at $3000 \mathrm{rpm}$ for 10 minutes at $4{ }^{\circ} \mathrm{C}$ and $200 \mu \mathrm{l}$ of the supernatant was transferred to a microplate where it was read in a spectrophotometer at $532 \mathrm{~nm}$. The TBARS concentrations were estimated by interpolating the determined absorbances in the samples with those determined in a standard curve, that was prepared through the dilution of a mother solution of 1,1,3 tetraethoxypropane (in ethanol $-0.42 \%$ ) in distilled water, thereby obtaining final concentrations 0 , $0.625,1.25,2.5,5.0,10.0,50.0,100.0 \mathrm{\mu mol} / \mathrm{L}$.

\section{Radiodermatitis assessment}

During RT treatment, the nursing team performed evaluations in order to detect side effects (radiodermatitis) and their degrees. All patients underwent at least three evaluations by the nursing team during treatment to detect radiodermatitis and its degrees. The radiodermatitis grading was guided by the CTCAE 4.03 (Medical Dictionary for regulatory Activities; MedDRA v12.0 Code 10061103, Dermatitis radiation) [20]:

- Grade one: Faint erythema or dry desquamation;

- Grade two: Moderate to brisk erythema; patchy moist desquamation, mostly confined to skin folds and creases; moderate edema;

- Grade three: Moist desquamation in areas other than skin folds and creases; bleeding induced by minor trauma or abrasion;

- Grade four: Life-threatening consequences; skin necrosis or ulceration of full-thickness dermis; spontaneous bleeding from involved site; skin graft indicated.

\section{Systematics of data collection}

After identifying the cases eligible for the study and application of the informed consent form, the following data were collected: age, gender, ethnicity, initial and final body weight, tumor stage, pathology, smoking habit, presence of associated comorbidities, as well as the use of symptomatic medications (analgesics/opioids) and the occurrence of radiodermatitis during treatment. In addition, plasma samples were obtained at the beginning ( $\left.T_{1}\right)$, in the half (T2) and at the end (T3) of the RT treatment for the quantification of TBARS, FRAP, as well as the plasma constituents that determine FRAP (Figure 1). 


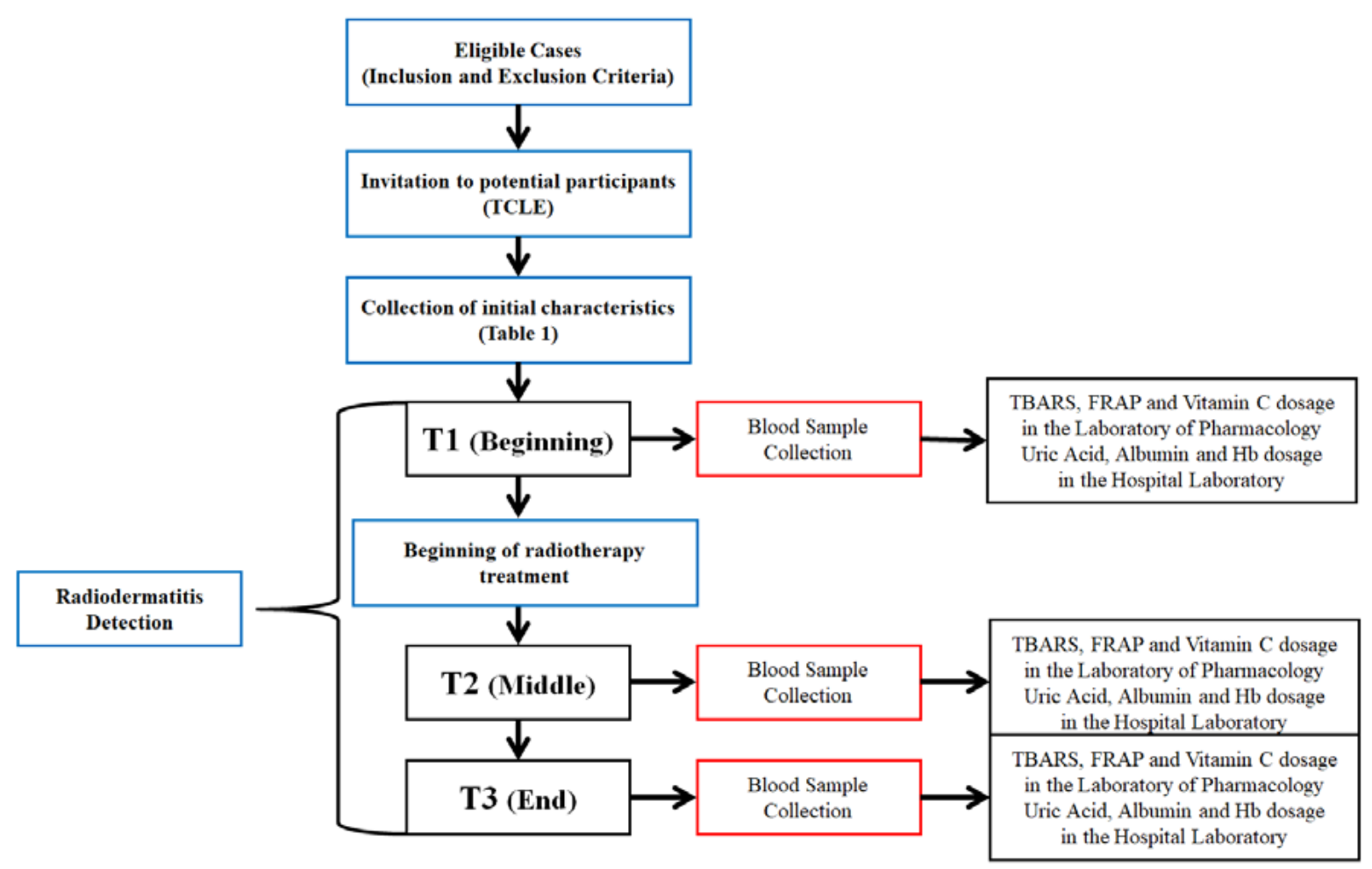

Figure 1 - Steps in the data collection procedure of the research

\section{Statistical analysis}

Statistical analysis was performed using IBM SPSS Statistics 20. Primarily, two-tailed tests were employed to confirm or refute the hypothesis that patients with overexpression of antioxidant defenses have less RT-induced radiodermatitis and, at the same time, patients with elevated oxidative stress have more RT-induced radiodermatitis than the others. The tests were defined according to the levels of expression and response, in the course and final analyzes, respecting the principles of event distributions, comparison between the groups and types of variables to be compared.

The descriptive statistics for the qualitative variables was performed through proportions. For the continuous variables, the means were calculated, as well as the standard deviations. The Mann-Whitney test was used to evaluate the differences between the means of the continuous variable distributions between the groups that developed radiodermatitis and the group without radiodermatitis. In parallel, the relationship between age or radiotherapy dose regimen with the development of grade two radiodermatitis was verified by Fisher's exact test. The intragroup paired analysis for comparison of continuous variables was done by paired $t$ test and Wilcoxon when necessary, being considered as significant values when $\mathrm{p}<0.05$.

\section{Results}

In the present study, 41 female patients with breast cancer were included, with a mean age of $57.5 \pm 11.2$ years. The 41 patients were followed for at least 16 and a maximum of 30 radiotherapy sessions, with an average of 21 sessions. The most prevalent ethnicity was white, with 30 (73.2\%) patients. Most patients were non-smokers, also 30 (73.2\%), 37 (90.2\%) patients did not use non-opioid analgesics and $41(100 \%)$ did not use opioids either before or during radiotherapy. The most prevalent histological type was infiltrating ductal carcinoma, with 30 out of the 41 patients (73.2\%). These patients weighed on average $77.7 \pm 16.5 \mathrm{~kg}$ at the beginning of the treatment. This body weight did not change significantly during treatment, since the mean weight at the end was $77.3 \pm 16.5 \mathrm{~kg}$. 
In the present study, it was also observed that the majority of the patients, 25 (60.9\%) patients followed up presented radiodermatitis during treatment, of which 15 (36.5\%) presented grade one and 10 (24.4\%) grade two, but none of them presented a grade higher than two.

The RT doses used in these patients varied around 46.9 \pm 5.7 Gy. The occurrence of grade two radiodermatitis was more frequent in patients submitted to RT by conventional doses, 8 patients, compared to those submitted to RT by hypofractionated doses, 2 patients; ( $80 \% \mathrm{X}$ $20 \% ; p=0.008$ ). On the other hand, there was no significant difference in the occurrence of grade two radiodermatitis among patients $\leq 60$ years and those $>60$ years $(60 \% \times 40 \%$; $p>0.05)$.
The data obtained in the present study showed that there were no significant differences in the values of FRAP, vitamin C, uric acid, albumin and $\mathrm{Hb}$, among the plasma samples obtained from the patients at the beginning and in the middle of the RT treatment. However, the value of FRAP, but not of vitamin C, uric acid, albumin and $\mathrm{Hb}$, were significantly higher at the end of the RT treatment, when compared to the values obtained at the beginning. These FRAP values, obtained at the end of treatment, were also significantly higher than those obtained in the middle of the treatment. In addition, significantly higher values of albumin were observed in the middle of the treatment, in comparison to the end (Table 1).

TABLE 1 - Non-enzymatic antioxidant defenses evaluated during the course of treatment.

\begin{tabular}{llll}
\hline & \multicolumn{1}{c}{ T1 } & \multicolumn{1}{c}{ T2 } & \multicolumn{1}{c}{ T3 } \\
\hline FRAP ( $\mu$ mol/L) & $1049.5 \pm 171.2$ & $1070.6 \pm 219.2$ & $1130.3 \pm 217.3$ \\
& $(41)$ & $(40)$ & $(38)^{*}+$ \\
Vitamin C (mg/dL) & $2.5 \pm 0.9$ & $2.5 \pm 1.1$ & $2.4 \pm 0.9$ \\
& $(34)$ & $(36)$ & $(33)$ \\
Uric Acid (mg/dL) & $5.2 \pm 1.2$ & $5.0 \pm 1.2$ & $5.0 \pm 1.2$ \\
& $(40)$ & $(40)$ & $(37)$ \\
Albumin (g/dL) & $3.9 \pm 0.1$ & $3.9 \pm 0.2$ & $3.9 \pm 0.2$ \\
& $(40)$ & $(40)$ & $(37)^{*}$ \\
Hemoglobin $(\mathbf{g} / \mathbf{d L})$ & $12.2 \pm 1.0$ & $12.7 \pm 0.8$ & $12.8 \pm 0.7$ \\
& $(41)$ & $(40)$ & $(38)$ \\
\hline
\end{tabular}

FRAP, ferric reducing ability of plasma; T1, Baseline; T2, Middle; T3, End. Values expressed as mean \pm standard deviation, in parentheses, sample numbers. " $p<0,05$ in $T_{2}$ to $T_{3} / t p<0,05$ in $T_{1}$ to $T_{3}$

The data obtained in the present study show that the values of FRAP, as well as vitamin C, uric acid, albumin and $\mathrm{Hb}$, determined in the patients at the beginning, middle and end of the RT treatment did not differ between patients who developed and those who did not develop radiodermatitis of any degree (Table 2). There were also no sig- nificant differences in FRAP, vitamin C, uric acid, albumin and $\mathrm{Hb}$, determined at the baseline, middle and the end of RT treatment among patients with grade two radiodermatitis, in relation to the others followed in the study (Table 3 ). 
TABLE 2 - Non-Enzymatic antioxidant defenses and the development of radiodermatitis during the course of treatment.

T1

T2

T3

$\operatorname{FRAP}(\mu \mathrm{mol} / \mathrm{L})$

Patients with radiodermatitis

Patients without radiodermatitis

$1068.2 \pm 160.8(25)$

$1020.3 \pm 188.0(16)$

1095.2 $202.2(24)$

$1159.6 \pm 173.6$ (22)

Vitamin C (mg/dL)

Patients with radiodermatitis

Patients without radiodermatitis

Uric Acid (mg/dL)

Patients with radiodermatitis

Patients without radiodermatitis

\section{Albumin (g/dL)}

Patients with radiodermatitis

Patients without radiodermatitis

\section{Hemoglobin ( $g / d L)$}

Patients with radiodermatitis

Patients without radiodermatitis

$2.3 \pm 0.8(20)$

$2.3 \pm 0.9(14)$

$5.2 \pm 1.4(24)$

$4.8 \pm 1.1(16)$

$3.9 \pm 0.2(24)$

$3.9 \pm 0.2(16)$

$12.2 \pm 1.2(25)$

$12.8 \pm 1.1(16)$

$1033.7 \pm 245.0(16)$

$1090.0 \pm 266.8(16)$

$2.4 \pm 1.1(20)$

$2.4 \pm 0.9(20)$

$3.0 \pm 1.1(16)$

$2.6 \pm 0.1(13)$

FRAP, ferric reducing ability of plasma; T1, Baseline; T2, Middle; T3; End. Values expressed as mean \pm standard deviation, in parentheses, sample numbers. No statistically significant differences were found.

TABLE 3- Non-enzymatic antioxidant defenses and the development of grade two radiodermatitis during the course of treatment.

\begin{tabular}{|c|c|c|c|}
\hline $\begin{array}{l}\text { VARIABLE } \\
\text { Groups }\end{array}$ & T1 & T2 & T3 \\
\hline \multicolumn{4}{|l|}{$\operatorname{FRAP}(\mu \mathrm{mol} / \mathrm{L})$} \\
\hline Patients with radiodermatitis grade 2 & $1135.0 \pm 216.3(10)$ & $1152.5 \pm 216.0(10)$ & $1191.6 \pm 172.6(10)$ \\
\hline Other patients & $1022.0 \pm 147.8(31)$ & $1043.4 \pm 217.1(30)$ & $1090.0 \pm 229.9(28)$ \\
\hline \multicolumn{4}{|l|}{ Vitamin $C(\mathrm{mg} / \mathrm{dL})$} \\
\hline Patients with radiodermatitis grade 2 & $2.3 \pm 0.8(09)$ & $2.3 \pm 1.0(09)$ & $2.0 \pm 0.9(08)$ \\
\hline Other patients & $2.6 \pm 0.9(25)$ & $2.7 \pm 1.2(27)$ & $2.6 \pm 0.9(25)$ \\
\hline \multicolumn{4}{|l|}{ Uric Acid (mg/dL) } \\
\hline Patients with radiodermatitis grade 2 & $5.9 \pm 1.9(10)$ & $5.6 \pm 1.5(10)$ & $5.6 \pm 1.7(10)$ \\
\hline Other patients & $4.8 \pm 0.9(30)$ & $4.8 \pm 1.1(30)$ & $4.9 \pm 1.0(27)$ \\
\hline \multicolumn{4}{|l|}{ Albumin $(g / d L)$} \\
\hline Patients with radiodermatitis grade 2 & $3.9 \pm 0.1(10)$ & $3.9 \pm 0.3(10)$ & $3.8 \pm 0.3(10)$ \\
\hline Other patients & $3.9 \pm 0.2(30)$ & $3.9 \pm 0.2(30)$ & $3.8 \pm 0.2(26)$ \\
\hline \multicolumn{4}{|l|}{ Hemoglobin (g/dL) } \\
\hline Patients with radiodermatitis grade 2 & $12.4 \pm 1.3(10)$ & $12.4 \pm 1.7(10)$ & $12.1 \pm 1.6(10)$ \\
\hline Other patients & $12.4 \pm 1.2(31)$ & $12.7 \pm 1.1(31)$ & $12.6 \pm 1.0(28)$ \\
\hline
\end{tabular}

FRAP, ferric reducing ability of plasma; T1, Baseline; T2, Middle; T3; End. Values expressed as mean \pm standard deviation, in parentheses, sample numbers. No statistically significant differences were found. 
In the present study, there were no significant differences in the TBARS values between the samples collected from the patients at the beginning (8.80 $\pm 5.86, n=35)$, middle $(7.56 \pm 4.01, n=37)$ and at the end $(7.49 \pm 3.52 ; n=36)$ of the RT treatment. The values of TBARS, obtained at the beginning, in the middle and at the end of the RT treatment, also did not differ significantly in patients who presented radiodermatitis in relation to those who did not. There were also no differences in TBARS, determined along the RT treatment, among patients who developed grade two radiodermatitis compared to the others (Table 4).

TABLE 4 - TBARS values ( $\mu \mathrm{mol} / L$ ) and radiodermatitis during the course of treatment

\begin{tabular}{llll}
\hline & \multicolumn{1}{c}{ T1 } & T2 & \multicolumn{1}{c}{ T3 } \\
\hline Any grade of radiodermatitis & & & \\
Patients with radiodermatitis & $8.0 \pm 4.5(23)$ & $7.8 \pm 3.7(22)$ & $7.4 \pm 3.3(21)$ \\
Other patients & $10.5 \pm 7.7(12)$ & $7.1 \pm 4.5(15)$ & $7.4 \pm 4.0(15)$ \\
Radiodermatitis grade two & & & \\
Patients with radiodermatitis grade 2 & $8.6 \pm 4.8(08)$ & $7.8 \pm 2.8(09)$ & $7.8 \pm 3.4(09)$ \\
Other patients & $8.9 \pm 6.2(27)$ & $7.4 \pm 4.4(28)$ & $7.3 \pm 3.6(27)$ \\
\hline
\end{tabular}

TBARS, thiobarbituric acid reactive substances; T1, Beginning; T2, Middle; T3, End. Values expressed as mean \pm tandard deviation, in parentheses, sample numbers. No statistically significant differences were found.

Finally, the values of TBARS, as well as FRAP and the components of FRAP (Vitamin C, Uric Acid, Albumin and $\mathrm{Hb}$ ) did not differ between patients undergoing hypofractionated doses of RT, compared to conventional, both at beginning, middle or at the end of treatment (Table 5). There was also no statistical difference in these parameters, determined at the beginning, middle or at the end of treatment, among patients with ages greater than and less than 60 years (Table 6).

TABLE 5 - Values of TBARS, FRAP and substances that determine FRAP in patients submitted to different radiotherapy doses.

T1

TBARS

Conventional

Hypofractioned

$\operatorname{FRAP}(\mu \mathrm{mol} / \mathrm{L})$

Conventional

Hypofractioned

Vitamin $C(\mathrm{mg} / \mathrm{dL})$

Conventional

Hypofractioned

Uric Acid (mg/dL)

Conventional

Hypofractioned
$7.0 \pm 3.7(14)$

$10.1 \pm 6.7(21)$

$1105.1 \pm 166.0(17)$

$1010.2 \pm 167.1(24)$

$2.6 \pm 1.0(15)$

$2.4 \pm 0.8$ (19)

$5.6 \pm 1.4(16)$

$4.7 \pm 1.1(24)$
T2

T3

$\begin{array}{ll}8.8 \pm 4.3(14) & 7.6 \pm 3.3(13) \\ 6.7 \pm 3.7(23) & 7.3 \pm 3.7(23)\end{array}$

$1110.8 \pm 189.2(16)$

$1162.8 \pm 190.3$ (14)

$1043.9 \pm 237.5$ (24)

$1111.4 \pm 233.3$ (24)

$\begin{array}{ll}2.3 \pm 1.3(12) & 2.6 \pm 1.1(12) \\ 2.8 \pm 1.0(24) & 2.3 \pm 0.9(21)\end{array}$

$5.4 \pm 1.2(16)$

$5.3 \pm 1.4(14)$

$4.7 \pm 1.2(24)$

$5.0 \pm 1.1(23)$ 


$\begin{array}{llll}\begin{array}{c}\text { Albumin }(\mathbf{g} / \mathbf{d L}) \\ \text { Conventional }\end{array} & 3.9 \pm 0.2(16) & 3.9 \pm 0.2(16) & 3.8 \pm 0.3(13) \\ \text { Hypofractioned } & 3.9 \pm 0.2(24) & 3.9 \pm 0.1(24) & 3.8 \pm 0.2(23) \\ \text { Hemoglobin }(\mathbf{g} / \mathbf{d L}) & & & \\ \text { Conventional } & 12.0 \pm 1.2(17) & 12.3 \pm 1.5(16) & 12.1 \pm 1.5(14) \\ \text { Hypofractioned } & 12.7 \pm 1.1(24) & 12.8 \pm 1.0(24) & 12.7 \pm 1.0(24)\end{array}$

FRAP, ferric reducing ability of plasma; T1, Beginning; T2, Middle; T3, End; TBARS: thiobarbituric acid reactive substances. Values expressed as mean \pm standard deviation, in parentheses, sample numbers. No statistically significant differences were found.

TABLE 6- Values of TBARS, FRAP and substances that determine FRAP in different age range

\begin{tabular}{|c|c|c|c|}
\hline Age & T1 & T2 & T3 \\
\hline \multicolumn{4}{|l|}{ TBARS } \\
\hline$\leq 60$ & $7.2 \pm 4.6(19)$ & $8.3 \pm 3.5(18)$ & $7.2 \pm 3.1(17)$ \\
\hline$>60$ & $10.8 \pm 6.7(16)$ & $6.8 \pm 4.4(19)$ & $7.5 \pm 4.0(19)$ \\
\hline \multicolumn{4}{|l|}{$\operatorname{FRAP}(\mu \mathrm{mol} / \mathrm{L})$} \\
\hline$\leq 60$ & $1025.1 \pm 192.5(21)$ & $1025.6 \pm 206.2(20)$ & $1106.7 \pm 215.8(18)$ \\
\hline$>60$ & $1075.3 \pm 146.2(20)$ & $1115.7 \pm 228.0(20)$ & $1151.7 \pm 221.9(20)$ \\
\hline \multicolumn{4}{|l|}{ Vitamin $C(\mathrm{mg} / \mathrm{dL})$} \\
\hline$\leq 60$ & $2.8 \pm 0.9(18)$ & $2.3 \pm 1.2(19)$ & $2.5 \pm 1.0(16)$ \\
\hline$>60$ & $2.2 \pm 0.7(16)$ & $3.0 \pm 0.9(17)$ & $2.4 \pm 1.0(17)$ \\
\hline \multicolumn{4}{|l|}{ Uric Acid (mg/dL) } \\
\hline$\leq 60$ & $5.1 \pm 1.49(20)$ & $4.9 \pm 1.3(20)$ & $4.9 \pm 1.4(18)$ \\
\hline$>60$ & $5.0 \pm 1.1(20)$ & $5.1 \pm 1.2(20)$ & $5.3 \pm 1.1(19)$ \\
\hline \multicolumn{4}{|l|}{ Albumin (g/dL) } \\
\hline$\leq 60$ & $3.9 \pm 0.1(20)$ & $3.9 \pm 0.2(20)$ & $3.8 \pm 0.2(17)$ \\
\hline$>60$ & $3.8 \pm 0.2(20)$ & $3.9 \pm 0.2(20)$ & $3.8 \pm 0.2(19)$ \\
\hline \multicolumn{4}{|l|}{ Hemoglobin (g/dL) } \\
\hline$\leq 60$ & $12.4 \pm 0.9(21)$ & $12.7 \pm 1.2(20)$ & $12.5 \pm 1.2(18)$ \\
\hline$>60$ & $12.5 \pm 1.4(20)$ & $12.6 \pm 1.4(20)$ & $12.5 \pm 1.2(20)$ \\
\hline
\end{tabular}

FRAP, ferric reducing ability of plasma; T1, Baseline; T2, Middle; T3, End; TBARS: thiobarbituric acid reactive substances. Values expressed as mean \pm standard deviation, in parentheses, sample numbers. No statistically significant differences were found.

\section{DISCUSSION}

Recent data reported by Instituto Nacional de Câncer show that breast cancer is one of the most prevalent type of cancer in Brazil, affecting mainly women. On the other hand, the male breast cancer is an uncommon disease, accounting for about $1 \%$ of all breast cancers $[2,21]$. This lower incidence of breast cancer in men justifies the fact that, in the present study, the studied population being constituted only by women. In this way, in 
the present study, it was decided to investigate women affected by this type of tumor due to its epidemiological importance and its high prevalence. The most prevalent histological type of breast cancer is ductal carcinoma, either infiltrating or in situ type [22]. Coincidentally, in the present study, these histological types comprised $85,4 \%$ of the sample. In situ ductal carcinoma is the early stage breast cancer, which usually has no capacity to develop metastasis. On the other hand, infiltrating ductal carcinoma may develop metastasis and is the most common type of breast cancer, with almost 70 to $80 \%$ of all cases $[23,24]$.

It has been questioned whether smoking is a risk factor for breast cancer. Some recent evidence still not suggest that smoking increases the risk of this type of cancer $[25,26]$. In the present study, the majority of the followed patients (73.2\%) were nonsmokers. However, it is important to emphasize that smoking is the greatest avoidable risk factor for illness and death in the world. It is related to various types of cancer (lung, oral cavity, larynx, pharynx, esophagus, stomach, pancreas, liver, kidney, bladder, cervix and leukemia), accounting for about $30 \%$ of cancer deaths. The main cancer associated with smoking is lung cancer, since smokers are up to 20 times more likely to have this type of cancer [27]. Thus, despite the data of the present study, it should be emphasized that there is no safe limit for tobacco use.

In the present study, few patients needed analgesics during the treatment and none needed opioids. In fact, according to the literature, the incidence of painful symptoms in patients with breast cancer is rare and the use of analgesics is generally unnecessary [28]. In addition, the followed patients did not have significant body mass changes along the treatment. This suggests that there were not RT-induced modifications of the body composition in these patients. This observation facilitated the interpretation of the presented data since it is known that the profile of lipid peroxidation can be modified depending on the body mass index. Actually, it has been reported that the increase in body mass is directly proportional to the lipid peroxidation profile [29, 30].

One of the most used treatments for breast tumors is RT. This modality of treatment, is fundamental to increase the survival of these patients [4, 5]. However, although considered less invasive, the RT is not free of adverse effects. It is known that approximately $90 \%$ of women submitted to RT for breast cancer have skin changes during treatment [31]. This is the reason why we decide to study patients affected by this type of cancer. In the present study, $60.9 \%$ of the followed up patients developed radiodermatitis during treatment, an incidence slightly lower than the reported by the literature [32]. Nevertheless, radiodermatitis is still the main collateral effect among these patients. Thus, approaches aiming to minimize this side effect is of great therapeutic interest. In the present study, the incidence of radiodermatitis in patients submitted to RT with hypofractionated doses was compared to the incidence in those submitted to RT with conventional doses. The hypofractionated dose protocol delivers a dose greater than 2 Gy per fraction, which corresponds to the total application of the day. It differs from the conventional dose protocol, which delivers at most 1.8 to 2.0 Gy per fraction. However, although the daily dose is higher in the RT with hypofractionated doses, the overall dose of the treatment is lower [33].

According to the literature, hypofractionated doses reduces the toxicity of RT treatment. In addition, RT with hypofractionated doses reduces the number of sessions and, consequently, reduces either the health professional's hours of work or the patient's displacements, being more convenient for the patient and less costly to the health system [33-36]. However, in the choice of the type of treatment, such advantages should be only considered as a bonus, since the main purpose must always be the therapeutic benefit. Notably, studies that compare RT with hypofractionated and conventional doses report divergent results, but do not evidence different toxicity among these modality of treatment. Thus, it can be argued that logistical advantages are sufficient to justify the choice of RT [33, 36].

The employed three-dimensional (3D)-RT with hypofractionated doses permits lower doses of radiation in normal tissue, thereby reducing the toxicity of the treatment [34]. In fact, in the present 
study, RT with hypofractionated doses caused less grade two radiodermatitis compared to RT with conventional doses. These data are in agreement with a randomized study, in which it was observed that RT with hypofractionated doses produce less acute toxicity and less fatigue to the patients in comparison to RT with conventional doses, facilitating thus the performance of their daily activities [37].

Radiodermatitis is a result of the aggression imposed by radiation on the skin tissues. The effects of radiation are mainly caused by the water radiolysis, generating highly reactive free radicals, which in excess cause oxidative stress in both tumor and healthy tissues [9-12]. All cellular components are susceptible of lipid peroxidation, in consequence of this elevation of free radicals, but the cell membranes are one of the most affected. This process leads to entails loss of cell membranes selectivity for ionic exchanges, thus releasing hydrolytic enzymes from lysosomes and forming cytotoxic products [38, 39]. These indirect effects of radiation, which occur through water radiolysis, correspond to approximately $75 \%$ of the injuries caused by RT on both healthy and tumor tissues.

Since the occurrence of radiodermatitis differs among the patients submitted to RT, we were interested in a better understanding of the physiological mechanisms by which the tissues protect themselves from radiation-induced oxidative stress. In fact, the present study is based on the hypothesis that the antioxidant defenses present in the body of the followed patients could attenuate or prevent the RT-induced radiodermatitis. The non-enzymatic antioxidant defenses, specifically, are a result of the presence of several constituents in biological fluids, among them uric acid, vitamin $\mathrm{C}$ and albumin [15]. Because they can be evaluated through simple and inexpensive biochemical analyzes and, mainly, because they are physiologically important, non-enzymatic antioxidant defenses were the focus of the present study.

The obtained data demonstrated an increment of FRAP at the end of treatment, compared to the values obtained at the beginning and in the middle of the protocol. This observation is intriguing be- cause it suggests that there was no consumption of FRAP-related antioxidant defenses along the RT treatment. Another interesting point to note is that this increment was not accompanied by significant increases in concentrations of uric acid, vitamin C and albumin, substances that confer antioxidant power on plasma and have a direct influence on FRAP [14, 15]. Curiously, it was observed a small elevation of albumin plasma concentration during the RT treatment, that returned at the normal level the end of the protocol. This elevation of albumin does not seem to be clearly related to the behavior of FRAP. Thus, these data suggest the participation of other plasma constituents, besides those mentioned, in the elevation of the antioxidant power of the plasma harvested of these patients at the end of the RT treatment, although it is known that uric acid and vitamin C exert around of $60 \%$ and $20 \%$, respectively, of the antioxidant capacity evaluated by FRAP [14-16].

The immediate consequence of RT-induced oxidative stress on tissues is the lipid peroxidation, that occurs in many cellular structures as well as in biological fluids. Among the products generated by the lipid peroxidation, MDA, that reacts with TBA, is one of the most important. Thus, elevations of TBARS mean higher production of MDA which, in turn, denotes a greater degree of oxidative stress. In the present study, no significant modifications of TBARS were observed along the RT treatment. This suggests that the systemic redox balance was maintained in these patients, despite the RT effects. These data, however, require a careful analysis because several studies suggest that radiation increases the oxidative stress in different tissues [11, 12]. What it can be stated is that, at least in these patients, the local oxidative stress did not lead to a systemic redox imbalance that could be detected by significant increases in TBARS. These data, perhaps, can justify the absence of systemic consequences of RT treatment were observed, such as weight loss or worsening of patient general condition throughout the treatment. This reinforces an already well-established concept that the effects of radiotherapy are local, occurring in both tumor and adjacent tissues. In the present study, 
we also evaluated lipid peroxidation in patients younger than 60 years, separately from those older than 60 years. This is because, as we know, aging is a condition characterized by an increase in oxidative stress [40,41]. However, in any of the age ranges we do not observe any significant modification of TBARS.

Finally, the central objective of the present study was to verify if the degree of oxidative stress and the antioxidant power determined by the FRAP in the plasma of patients with breast cancer submitted to RT differ among those who present radiodermatitis during treatment. If differences were observed, the determination of TBARS and/ or FRAP in the plasma of patients submitted to RT could predict the risk of occurrence of radiodermatitis or even assist in determining the severity of this important side effect. Indeed, these simple and inexpensive plasma analysis could be used as important allies in therapeutic decision-making for the treatment of tumors. However, the presented data do not show significant modifications of TBARS, or even FRAP, in patients who developed radiodermatitis. These changes were not observed even in the patients who presented more intense radiodermatitis, such as grade two radiodermatitis. The present study does not rule out possible relationship between oxidative stress and the occurrence of radiodermatitis. Nor does it rule out the existence of a relationship between occurrence or severity of radiodermatitis and efficiency of the antioxidant defenses. However, for these possible relationships to be verified, other experimental approaches through other analytical techniques, perhaps more invasive, should be performed.

In the present study, it was observed that the power of antioxidant defenses assessed by FRAP in plasma increases along the RT treatment to which breast cancer patients are submitted. This elevation, however, was not accompanied by significant changes of the oxidative stress in the plasma of these patients. In addition, in the present study, there were no changes in the values of TBARS and/or FRAP among patients who developed radiodermatitis.

\section{Notes}

\section{Funding}

Financial support for this study was provided by the Fundação de Amparo à Pesquisa de São Paulo (FAPESP) through a Regular Research Grant (Grant No. 2013/22655-9) and Coordination for the Improvement of Higher Education Personnel (CAPES).

\section{Conflicts of interest disclosure}

The authors declare no competing interests relevant to the content of this study.

\section{Authors' contributions.}

All the authors declare to have made substantial contributions to the conception, or design, or acquisition, or analysis, or interpretation of data; and drafting the work or revising it critically for important intellectual content; and to approve the version to be published.

\section{Availability of data and responsibility for the results}

All the authors declare to have had full access to the available data and they assume full responsibility for the integrity of these results.

\section{REFERENCES}

1. Torre LA, Bray F, Siegel RL, Ferlay J, Lortet-Tieulent J, Jemal A. Global Cancer Statistics, 2012. CA Cancer J Clin. 2015;65(2):87-108. https://doi.org/10.3322/caac.21262

2. Instituto Nacional de Câncer José Alencar Gomes da Silva, Brasil. Apresentação e Introdução [Presentation and Introduction]. INCA. 1996-2020. [cited 2020 Abr 19]. Available from: https://www.inca.gov.br/estimativa/introducao

3. Bray F, Ferlay J, Soerjomataram I, Siegel RL, Torre LA, Jemal A. Global cancer statistics 2018: GLOBOCAN estimates of incidence and mortality worldwide for 36 cancers in 185 countries. CA Cancer J Clin. 2018; 68(6):394-24. https://doi.org/10.3322/caac.21492

4. Darby S, McGale P, Correa C, Taylor C, Arriagada R, Clarke M, Cutter D, Davies C, Ewertz M, Godwin J, Gray R, Pierce L, Whelan T, Wang Y, Peto R. Effect of radiotherapy after breast-conserving surgery on 10-year recurrence and 15-year breast cancer death: meta-analysis of individual patient data for 10,801 women in 17 randomised trials. Lancet. 2011; 378(9804):1707-16. https://doi.org/10.1016/S0140-6736(11)61629-2 
5. McGale P, Taylor C, Correa C, Cutter D, Duane F, Ewertz M, Gray R, Mannu G, Peto R, Whelan T, Wang Y, Wang Z, Darby S. Effect of radiotherapy after mastectomy and axillary surgery on 10-year recurrence and 20-year breast cancer mortality: meta-analysis of individual patient data for 8135 women in 22 randomised trials. Lancet. 2014; 383(9935):2127-35. https://doi. org/10.1016/S0140-6736(14)60488-8

6. Iliakis G, Dahm-Daphi J, Dikomey E. DNA repair and cell cycle regulation after ionizing irradiation. In: Molls $M$, Vaupel P, Nieder C, Anscher MS, editors. The impact of tumor biology on cancer treatment and multidisciplinary strategies. Berlin: Springer; 2009. p. 251-72. https://doi. org/10.1007/978-3-540-74386-6_14

7. West CM, Barnett GC. Genetics and genomics of radiotherapy toxicity: towards prediction. Genome Med. 2011; 3(8):52. https://doi.org/10.1186/gm268

8. O'Driscoll M, Jeggo PA. The role of double-strand break repair - insights from human genetics. Nat Rev Genet. 2006; 7(1):45-54. https://doi.org/10.1038/nrg1746

9. Zhao W, Diz DI, Robbins ME. Oxidative damage pathways in relation to normal tissue injury. $\mathrm{Br} J$ Radiol. 2007; 80(1):23-31. https://doi.org/10.1259/bjr/18237646

10. Chistiakov DA, Voronova NV, Chistiakov PA. Genetic variations in DNA repair genes, radiosensitivity to cancer and susceptibility to acute tissue reactions in radiotherapy-treated cancer patients. Acta Oncol. 2008; 47(5):80924. https://doi.org/10.1080/02841860801885969

11. Lim KH, Lee CY, Earnest A, Seet RC, Halliwell B. Does radiotherapy increase oxidative stress? A study with nasopharyngeal cancer patients revealing anomalies in isoprostanes measurements. Free Radic Res. 2010; 44(9):1064-71. https://doi.org/10.3109/10715762.2010.499906

12. Azzam El, Jay-Gerin JP, Pain D. Ionizing radiation-induced metabolic oxidative stress and prolonged cell injury. Cancer Lett. 2012; 327(1-2):48-60. https://doi.org/10.1016/j.canlet.2011.12.012

13. Schreiber GJ, Meyers AD. General principles of radiation therapy. [online publication]; 2018 [cited 2020 Jul 19]. Available from https://emedicine.medscape. com/article/846797-overview

14. Chies AB, Munhoz GC, de Oliveira PB. Desafios relacionados à avaliação do estresse oxidativo no processo de envelhecer. RBCEH. 2019; 16(1):38-43. https://doi. org/10.5335/rbceh.v16i1.9770

15. Benzie IF, Strain JJ. The ferric reducing ability of plasma (FRAP) as a measure of "antioxidant power": the FRAP assay. Anal Biochem. 1996; 239(1):70-6. https://doi.org/10.1006/abio.1996.0292

16. Reddy PE, Manohar SM, Reddy SV, Bitla AR, Vishnubhotla S, Narasimha SRPVL. Ferric reducing ability of plasma and lipid peroxidation in hemodialysis patients: intradialytic changes. Int J Nephrol Urol. 2010; 2(3):414-21
17. Ohkawa H, Ohishi N, Yagi K. Assay for lipid peroxides in animal tissues by thiobarbituric acid reaction. Anal Biochem. 1979; 95(2):351-58. https://doi.org/10.1016/0003-2697(79)90738-3

18. Yagi K. Assay for serum lipid peroxide level and its clinical significance. In: Yagi K, editor. Lipid Peroxides in Biology and Medicine. New York (NY): Academic Press; 1982. p. 223-242. https://doi.org/10.1016/B978-0-12768050-7.50020-2

19. Wills ED. Mechanism of lipid peroxide formation in animal tissues. Biochem J. 1966; 99(5) 667-76. https:// doi.org/10.1042/bjog90667

20. Zenda S, Ota Y, Tachibana H, Ogawa H, Ishii S, Hashiguchi C, Akimoto T, Ohe Y, Uchitomi Y. A prospective picture collection study for a grading atlas of radiation dermatitis for clinical trials in head-and-neck cancer patients. J Radiat Res. 2016; 57(3):301-06 https://doi.org/10.1093/jrr/rrvog2

21. Araújo IBS, Leite CB, Amorim TO, Silva ANL, Fernandes RSQ, Carmo MS. Câncer de mama em homens. Rev Investig Biomed. 2018; 10(3):272-79. Brazilian. https:// doi.org/10.24863/rib.v10i3.347

22. American Cancer Society, United States of America. Breast Cancer, Understanding a breast cancer diagnosis. Types of breast cancer. 2019. [cited $2020 \mathrm{Apr}$ 26]. Available from: https://www.cancer.org/cancer/ breast-cancer/understanding-a-breast-cancer-diagnosis/types-of-breast-cancer.html

23. Antonio Cândido de Camargo Cancer Center. Tipos de Câncer, Mama. [online publication]; 2018 [cited 2020 Apr 26]. Available from: https://accamargo.org. br/tipos-de-cancer/mama

24. United States of America. National Institute for Health (NIH). National Cancer Institute. Cancer Types. Breast Cancer. Breast cancer treatment (Adult) (PDQ $®)$ - Health professional version., Histopathologic classification of breast cancer. 2018. [cited 2020 Apr 26]. Available from: https://www.cancer.gov/types/breast/hp/breast-treatment-pdq\#link/_18

25. Filho VW, Mirra AP, López RVM, Antunes LF. Tabagismo e câncer no Brasil: evidências e perspectivas. Rev Bras Epidemiol. 2010; 13(2):175-187. https://doi. org/10.1590/S1415-790X2010000200001

26. Brasil. Ministério da Saúde. Instituto Nacional de Câncer José Alencar Gomes da Silva (INCA).Tipos de câncer. Câncer de mama. 2020. [cited 2020 Abr 19]. Available from: https://www.inca.gov.br/tipos-de-cancer/cancer-de-mama

27. Brasil. Ministério da Saúde. Instituto Nacional de Câncer José Alencar Gomes da Silva (INCA). Tabagismo. Causas e prevenção. Tabagismo. 2020. [cited $2020 \mathrm{Abr}$ 19]. Available from: https://www.inca.gov.br/tabagismo

28. Spence RAJ, Johnston PG. Oncologia. Rio de Janeiro: Guanabara; 2003. 
29. Olusi SO. Obesity is an independent risk factor for plasma lipid peroxidation and depletion of erythrocyte cytoprotectic enzymes in humans. Int J Obes Relat Metab Disord. 2002; 26(9):1159-64. https://doi. org/10.1038/sj.ijo.0802066

30. Melissas J, Malliaraki N, Papadakis JA, Taflampas P. Kampa M, Castanas E. Plasma antioxidant capacity in morbidly obese patients before and after weight loss. Obes Surg. 2006; 16(3):314-20. https://doi. org/10.1381/096089206776116444

31. Porock D, Kristjanson L. Skin reactions during radiotherapy for breast cancer: the use and impact of topical agents and dressings. Eur J Cancer Care. 1999; 8(3):143-53. https://doi.org/10.1046/j.1365-2354.1999.00153.x

32. Chen PY, Wallace M, Mitchell C, Grills I, Kestin L, Fowler A, Martinez A, Vicini F. Four-year efficacy, cosmesis, and toxicity using three-dimensional conformal external beam radiation therapy to deliver accelerated partial breast irradiation. Int J Radiat Oncol Biol Phys. 2010; 76(4):991-97. https://doi.org/10.1016/j. ijrobp.2009.03.012

33. Ray KJ, Sibson NR, Kiltie AE. Treatment of breast and prostate cancer by hypofractionated radiotherapy: potential risks and benefits. Clin Oncol ( $R$ Coll Radiol). 2015; 27(7):420-26. https://doi.org/10.1016/j. clon.2015.02.008

34. Ritter M. Rationale, conduct, and outcome using hypofractionated radiotherapy in prostate cancer. Semin Radiat Oncol. 2008; 18(4):249-56. https://doi.org/10.1016/i.semradonc.2008.04.007

35. Parthan A, Pruttivarasin N, Davies D, Taylor DC, Pawar V. Bijlani A, Lich KH, Chen RC. Comparative cost-effectiveness of stereotactic body radiation therapy versus intensity-modulated and proton radiation therapy for localized prostate cancer. Front Oncol. 2012; 2:81. https://doi.org/10.3389/fonc.2012.00081

36. Sethukavalan P, Cheung P, Tang $\mathrm{Cl}$, Quon H, Morton G, Nam R, Loblaw A. Patient costs associated with external beam radiotherapy treatment for localized prostate cancer: the benefits of hypofractionated over conventionally fractionated radiotherapy. Can J Urol. 2012; 19(2):6165-9.

37. Shaitelman SF, Schlembach PJ, Arzu I, Ballo M, Bloom ES, Buchholz D, Chronowski GM, Dvorak T, Grade E, Hoffman KE, Kelly P, Ludwig M, Perkins GH, Reed V, Shah S, Stauder MC, Strom EA, Tereffe W. Woodward WA, Ensor J et al. Acute and Short-term Toxic Effects of Conventionally Fractionated vs Hypofractionated Whole-Breast Irradiation: A Randomized Clinical Trial. JAMA Oncol. 2015;1(7):931-41. https://doi.org/10.1001/jamaoncol.2015.2666

38. Mello Filho AC, Hoffmann ME, Meneghini R. Cell killing and DNA damage by hydrogen peroxide are mediated by intracellular iron. Biochem J. 1984; 218(1):273-5. https://doi.org/10.1042/bj2180273

39. Hershko C. Mechanism of iron toxicity and its possible role in red cell membrane damage. Semin Hematol. 1989; 26(4):277-85
40. Shan XQ, Aw TY, Jones DP. Glutathione-dependent protection against oxidative injury. Pharmacol Ther. 1990; 47(1):61-71. https://doi.org/10.1016/01637258(90)90045-4

40. Shan XQ, Aw TY, Jones DP. Glutathione-dependent protection against oxidative injury. Pharmacol Ther. 1990; 47(1):61-71. https://doi.org/10.1016/01637258(90)90045-4

\section{Guilherme Costa Munhoz}

Master in Health and Aging by the Marilia Medical School (FAMEMA, Marilia, SP, Brazil), professor of Internal Medicine at Clinic Hospital of Marilia Medical School (HC-FAMEMA, Marilia, SP, Brazil).

\section{Gustavo Viani Arruda}

PhD in Medicine and professor of Radiotherapy at Ribeirão Preto Medical School (FMRP-USP, Ribeirão Preto, SP, Brazil).

\section{Marcela Maris Madeira Lana Soares}

Master in Health Education by the Marilia Medical School (FAMEMA, Marilia, SP, Brazil), nurse at Department of Radiation Oncology of Clinic Hospital of Marilia Medical School (HC-FAMEMA, Marilia, SP, Brazil).

\section{Dayanne Guttmann Batista}

Resident of Physical Medicine and Rehabilitation at Clinic Hospital of Marilia Medical School (HC-FAMEMA, Marília, SP, Brazil).

\section{Agnaldo Bruno Chies}

PhD in Pharmacology by the Ribeirão Preto Medical School (FMRP-USP, Ribeirão Preto, SP, Brazil), professor of Pharmacology and Experimental Therapeutics at Marilia Medical School (FAMEMA, Marilia, SP, Brazil).

\section{Mailing address:}

Guilherme Costa Munhoz

Faculdade de Medicina de Marilia

Av. Monte Carmelo, 800

Fragata, 17519-030

Marilia, SP, Brasil 